\title{
Iluminismo, precisa-se!
}

\section{Enlightenment needed}

Ernesto Manuel de Melo e Castro

Poeta

ercastropt@gmail.com

Resumo: Conferência lida no dia 23 de outubro de 2019, na Universidade Federal de São Paulo, campus Guarulhos, durante o Colóquio "Pensar a palavra-experiência": homenagem a E.M. de Melo e Castro.

Palavras-chave: poesia portuguesa contemporânea; experimentação; vanguarda.

Abstract: Conference read on October 23, 2019, at the Federal University of São Paulo, Guarulhos campus, during the Colloquium "Pensar a palavra-experiência": Homenagem a E.M. de Melo e Castro.

Keywords: contemporary portuguese poetry; experimentation; vanguard.

\section{Observações Preliminares}

1. Poderá dizer-se que o Iluminismo do século XVIII foi antecipado por certos aspectos da cultura medieval dos séculos XII e XIII? Tal pergunta de facto vem ao encontro de trabalhos meus sobre as origens remotas da IA e suas bases combinatórias com Ramon Lull mas também das origens da lírica portuguesa com as cantigas de amigo.

2. Mas logo me ocorreu que o salto semiótico entre o agora e a Idade Média ocorreria numa concepção do impreciso na sociodinâmica da cultura, o que me recordou do meu Mestre e depois amigo Abraham Molles e das suas aulas e conferências extraordinárias cheias de saltos heurísticos imprevistos, propostas transgressivas e reveladoras de um pensamento não só filosófico como poético. 
3. Por isso imaginei que a minha actual e de sempre, actividade poética, mas também da leitura recente de uma belíssima História da ficção científica, de Adam Roberts, que remonta às origens desse gênero literário em textos medievais, poderia aproximar poesia e ficção científica, pois ambas trabalham com a invenção e com as palavras, podendo colocar a questão se a ficção científica é poesia ou se inversamente a poesia é ficção científica...

4. Assim sendo... ou probabilisticamente, podendo ser, organizei esta minha minha comunicação no triângulo semiótico de Poesia/Ficção Científica/Inteligência Artificial. Tenho sempre presente que por Iluminismo se entende um movimento filosófico caracterizado pela centralidade da ciência e da racionalidade crítica como questionamento implicando a recusa de todas as formas do dogmatismo.

5. Não respondendo por enquanto a estas questões, inicio a minha exposição com dois videopoemas construídos a partir de imagens fractais criadas por mim no programa Fractint, no começo do século XXI.

\section{Comunicação}

Para iniciar esta minha comunicação proponho a leitura do seguinte fragmento de um texto que publiquei como posfácio do meu livro de poemas No limite das coisas, de 2003, com o seguinte título: "Quando o futuro é presente":

Todos sabemos que a media é a mensagem, mas temos de deixar de fingir que ignoramos que só a media existe. Forças pesadas continuarão a tentar considerar-nos apenas como efeitos especiais numa outra superprodução que tem por fim reduzir as dimensões do próprio globo terrestre a uma ínfima partícula desprezível, mas no entanto de peso insuportável até para o próprio Atlas. Apontamnos a desmaterialização para pesadamente nos diminuírem e assim voltarmos a ser escravos não se sabe já de quem nem para quê, visto que os deuses se ausentaram do processo e, se ainda existem, esperam-nos em outras galáxias...

No entanto, o que dizemos é o que somos e o que vemos é o que existimos. O que inventamos é o que certamente seremos, com 
um arbítrio que se diz livre. A luta entre o aumento totalitário do peso e a complexidade crescente dos elementos leves da nossa percepção acelerada está ainda no começo, mas já é o índice de que a superprodução em que estamos envolvidos e a que chamamos vida, se transformará de material em virtual, de global em sideral, para ser totalitária em vez de poética. Sim, poética porque invenção de si própria nos limites e transgressões paracinestésicas e transparentes. Isto porque, se os media são a mensagem, então a nossa percepção é o que existimos e o que escrevemos é o que somos, mas também o que desejamos nem sempre é o que seremos, numa indeterminada interactividade poliédrica e em transformações inesperadas e irrepetíveis.

Assim, a virtualidade caóticamente acelerada poderá vir a dizernos que o futuro é o único tempo conceptual em que a energia que somos projecta a sua leveza e por isso se delineia em formas leves e fluidas.

Desde há muitos séculos só os poetas e os visionários alucinados se apercebem desta evidência: o peso esmaga mas a leveza liberta. (MELO E CASTRO, 2003, p. 48).

\section{$* * *$}

Segundo um notável artigo de Edson Aran, publicado na Folha de São Paulo, em 18 de agosto de 2018, sobre as conseqüências para o mundo do trabalho no globo terrestre, da já presente inteligência artificial, com o título "Esqueça crachá e carteira de trabalho: agora tudo é volátil, incerto, complexo e ambíguo". Neste artigo apresentam-se os prós e os contras daquilo a que já se pode chamar a nova revolução digital que rapidamente produzirá transformações sociais e culturais com repercussões globais na nossa vida. Mas o que me despertou mais interesse foram justamente as quatro características já em curso dessas transformações indicadas pela sigla de origem nos Estados Unidos, V.I.C.A, ou seja, Volátil, Incerto, Complexo e Ambíguo. É que estas qualidades atribuídas às modificações sociais e econômicas resultantes da referida inteligência artificial, são conceptos característicos da poesia e são precisamente usados para caracterizar a poesia experimental praticada desde os anos 50 e 60 do século XX até a atualidade. De facto, a ambigüidade, a complexidade, e a fluidez ou leveza são parâmetros poéticos e críticos da mais avançada poesia das últimas décadas e constituem-se como índices semióticos das mais recentes manifestações 
artísticas. De facto a exposição de todo o meu trabalho poético que em 2006 realizei no Museu de Arte Contemporânea de Serralves na cidade do Porto em Portugal foi "O caminho do leve".

Será que finalmente as barreiras tradicionais entre arte e tecnologia podem ser abolidas pelo advento da inteligência artificial? Ou será tudo ficção científica, podendo dizer-se que poesia é ficção científica? Ou que reciprocamente a mais actual ficção científica é poesia?

Por uma casual coincidência quando escrevia as questões que acabo de formular, recebi por email as provas do último número da revista portuguesa A Ideia (número do outono de 2018) nelas descobri dois artigos sobre a grande escritora de ficção científica Ursula Kroeber Le Guim! É de um desses artigos de autoria de Ana da Palma, que faço o seguinte recorte:

Ursula K. Le Guim (nos seus livros) deixou-nos universos atravessados pelo perfume de uma flor nocturna cujo aroma percorre triliões de quilómetros. Universos conectados por borboletas viajantes espalhando pólen e palavras. Por um lado trata-se do universo em que vivemos... uma vida cheia... ela viu a grande depressão, a segunda guerra mundial, as bombas atómicas sobre o Japão, a guerra fria mundial, a repressão colonial a devorar corpos, sentiu as guerras colonialistas... viu o fim da URSS, as migrações sem fim de multidões perdidas no Oriente Médio... e as soluções a curto prazo que têm efeitos negativos sobre a vida de todos nós... Mas a lucidez das suas palavras também nos ensina que pode haver uma outra forma de viver quando diz: Nós vivemos no capitalismo; seu poder parece inevitável; o mesmo fez os direito dos reis. Qualquer poder humano pode ser enfrentado e mudado por seres humanos. A resistência e a mudança geralmente começam na arte e muitas vezes na nossa arte... a arte das palavras (LE GUIM apud PALMA, 2018, s/p).

A arte das palavras que se sintetiza na poesia e pode articular-se geneticamente com a ficção científica, ou seja, com a fantasia e o rigor da inovação que é sempre o dizer da verdade e da liberdade. Valores esses cujo âmbito é universal e intemporal. As interrogações andam no ar...

É assim possível, se não inevitável, darmos um salto no tempo e procurarmos as luzes que poderão iluminar o nosso caminho nos dois sentidos, para a frente ou para trás... ao encontro das vozes que mais nos podem revelar o como e o porquê do nosso sentir e pensar contemporâneo. 
Nesse intento e necessidade poderemos encontrar pontos luminosos como por exemplo os poetas medievais do Cancioneiro de Amigo em português e o seu/nosso contemporâneo Ramon Lull do século XIII, no arriscado entender do que somos ou almejamos ser quando adotamos como nossas as mais arriscadas inovações tecnológicas resumidas por exemplo nas expressões "inteligência artificial" ou "singularidade tecnológica", de Ray Kurzweil. Nesta perspectiva, Ramom Lull representa para nós um raio de luz que da obscura Idade Média chega até nós como mito também da inventividade e da inquietação, já que na sua juventude ele foi um atrevido namorador e é interessante referir o seguinte poema pícaro do poeta português nosso contemporâneo Alexandre O'Neill:

\author{
Raimundo Lulio, a mulher casada \\ Que cortejaste, que perseguiste \\ Até entrares, a cavalo, pela igreja \\ Onde fora rezar \\ Mudou-te a vida quando te mostrou \\ (é isto que amas?) \\ De repente a podridão do seio. \\ (O’NEILL, 1982, p. 32).
}

De facto, este episódio biográfico regista o momento crucial da vida de Ramon Lull que de libertino se transformou em inventor, construindo com papel e linha as primeiras máquinas combinatórias que são pequenos objectos que eu já tive o previlégio de ter nas minhas mãos quando fui a Palma de Maiorca de propósito para estudar a sua grande arte maior!

De facto, define-se uma arqueologia do contemporâneo digital se traçarmos uma linha direta conectando Ramon Lull, um catalão do século XIII a Nicholas Negroponte, um norte-americano do século XX. Tal linha de comunicação passará necessariamente pelo filósofo alemão Leibniz, do século XVII, que acreditava que todos os problemas do pensamento se poderiam resolver pelo cálculo. No entanto, quatro séculos antes, Ramon Lull estava convencido de que poderia demonstrar aos muçulmanos a superioridade da fé católica, através de operações mecânicas de vários engenhos combinatórios que inventou e realizou em papel ou apenas projetou e desenhou. Nessa missão religiosa mas também científica empenhou toda a sua longa vida, embora nunca tivesse obtido o reconhecimento desejado. 
Ambos, Ramon Lull e depois Leibniz, estavam intimamente convencidos de que a natureza imaterial tanto do pensamento como da fé se poderiam manifestar e comunicar através de construções rigorosas exteriores ao próprio pensamento e à fé religiosa. Ramon Lull usou operações de lógica combinatória realizadas sem a intervenção nem do pensamento humano nem divino, mas sim por esquemas geométricos, quadros, triângulos e círculos, articulados entre si, onde estavam inscritos os conceitos simples a combinar e as propriedades e atributos do Deus católico. Esses pequenos e frágeis instrumentos que ele próprio construía constituíam, com as exemplificações e conclusões certas e irrecusáveis a que permitiam chegar, a sua Arte Maior, que lecionou em Paris e em Roma, mas também em toda a Europa e Norte da África, respondendo também a todas as questões postas pelos seus discípulos. Mas sem conseguir convencer nem o papa nem os muçulmanos, que obviamente, não podiam aceitar, por razões diferentes, um conhecimento religioso que não fosse obtido pela fé ou pela revelação divina. No entanto, Ramon Lull foi o inventor de uma nova lógica não aristotélica, a lógica combinatória que hoje impregna a literatura experimental, realizada ou não, usando instrumentos informáticos.

Quanto a Leibniz, dele diz Wolfgang Rod:

A aplicação do cálculo a problemas concretos exige a interpretação do conteúdo, isto é, dos signos simples que nele ocorrem e que, por sua vez, se referem a todos os signos complexos. Leibniz esperava poder listar completamente os conceitos associados a símbolos simples e, assim, elaborar um alfabeto do pensamento a partir do qual seriam formados todos os conceitos compostos. De acordo com esta concepção leibniziana de lógica, o cálculo (calculus universalis) doutrina geral dos signos (characteristica universalis) e o alfabeto do pensamento estão intimamente relacionados. (ROD, 2008, p. 56)

O alfabeto do pensamento, para Leibniz, constituiria o instrumento que, utilizando o cálculo lógico, permitiria formular todos os pensamentos possíveis, independentemente do significado ou conteúdo semântico, porque, esse, dependia dos signos simples de que se partia para a obtenção dos signos complexos desejados e possíveis e suas interpretações.

Temos, portanto, aqui, uma computação rigorosa a produzir ideias novas, ditas compostas ou complexas. Mas como o intento de Leibniz é universal, o alfabeto do pensamento a constituir deveria ser formado 
por uma seleção de signos simples (tal como o alfabeto é composto por letras) que permitiriam formular todos os signos complexos possíveis, portanto todos os conceitos do pensamento humano!

Assim a arte maior (combinatória) de Ramon Lull e o alfabeto do pensamento de Leibniz, configuram aquilo a que nós hoje chamamos de computador, máquina de calcular rigorosa e universal que, usando um código digital, permite fazer tudo e dizer tudo o que o homem desejar, podendo mesmo ir além desses desejos ou expectativas, como é claramente a exploração combinatória, mas também randômica que possibilita a produção de obras de arte, ditas infoarte e infopoesia, e a geração de imagens fractais ou de caos determinista. Mas também permite todas comunicações, pluridirecionais e simultâneas, matematicamente possíveis, que a internet configura. E assim chegamos a Nicholas Negroponte e ao famoso código binário a que chamamos digital.

Negroponte, no seu livro $A$ vida digital, já de 1995, mas que permanece atual e pode ser considerado como uma 'bíblia' da comunicação digital, apresenta-nos um estudo comparativo entre os átomos pesados, lentos e caros da era industrial e os bits (unidades de informação), sem massa nem volume, que viajam à velocidade da luz e que totalmente alteram e transformam a natureza de informar e o significado de comunicar.

Como já referi, o outro feixe de luz que nos vem da Idade Média, iluminando toda a poesia em português é constituído pelas cantigas de amigo, que são a verdadeira fonte de toda a poesia galaico-portuguesa, não se podendo confundir essa poesia com as produções poéticas dos trovadores provençais que são da mesma época, ou seja, dos séculos XII e XIII.

É que as cantigas de amigo têm características próprias morfológicas e sintáticas, únicas e típicas na Península Ibérica. A primeira dessas características é que sendo de autores masculinos são escritas no feminino, isto é, a sua voz é quase sempre de uma jovem mulher. As outras características são expostas por exemplo no livro $D o$ cancioneiro de amigo, de Stephen Reckert e Helder Macedo e podem ser sinteticamente resumidas, como passo já a referir em duas cantigas que me parecem exemplificarem com especial nitide (inconsciente e como quem diz subliminarmente) na maneira como se processa através de signos lingüísticos, a relação mútua entre o poeta e a sua persona feminina, sintetizada em alguns conceitos chave, geralmente dualidades e não raro antíteses, incluindo as seguintes categorias: o tempo e o espaço, $\mathrm{o}$ real e o imaginário, a morte e o amor, o eu e o outro, o destino e a 
liberdade, a natureza e a sociedade, Deus e os signos mesmos em que óbvia e forçosamente se exprimem.

É que o tempo nas cantigas de amigo é invariavelmente subjectivo e pessoal e o espaço define-se com o mesmo critério vago e relativista. Esta relatividade não nos surpreende no contexto em que tempo e espaço são encarados automaticamente como simples manifestações contingentes do eterno e do infinito. As implicações desta mesma atitude são mais curiosas e originais quando é o valor da realidade física que se põe em questão, como é o caso de muitas cantigas de amigo em que o paralelismo e a repetição são os valores da comunicação. Vejamos então os dois exemplos de autoria do rei de Portugal, Dom Dinis:

Levantou-s'a velida

Levantou-s'alva

E vai lavar camisas

Em o alto

Vai-las lavar alva

Levantou-s a louçãa

Levantou's a alva

E vai lavar delgadas

Em o alto

Vai-las lavar alva

Vai lavar camisas

Levantou-s alva

$O$ vento lhas desvia

Em o alto

Vai-las lavar

E vai lavar delgadas

Levantou-s alva

$O$ vento lhas levava

Em o alto

Vai-las lavar alva

$\mathrm{O}$ vento lhas desvia

Levantou's alva

Meteu's alva em ira

Em o alto

Vai'las lavar alva 
O vento lhas levava

Levantou's alva

Meteu's alva em senha

Em o alto

Vai-las lavar alva

(RECKERT; MACEDO, 1996, p. 43).

Veja-se outra cantiga de Dom Dinis:

Ma madre velida

Vou-ma la baila

Do amor

Ma madre loada

Vou-ma bailada

Do amor

Vou-ma la bailia

Que fazem em vila

Do amor

Vou-m'a a la bailada

Que fazem em casa

Do amor

Que fazem em vila

Do qu'eu bem queria

Do amor

Que fazem em casa

Do qu'eu muit'amava

Do amor

Do qu'eu bem queria

Chamar-m'am garrida

Do amor

(RECKERT; MACEDO, 1996, p. 34).

E esta cantiga de Pero Meogo:

- Digades filha, mya filha velida

Porque tardaste na fontana fria

Os amores ey. 
- Digades filha, mya filha louçana

Porque tardaste na fria fontana

Os amores ey.

- Tardey mya madre na fontana fria

Cervos do monte a aúgua volvian.

Os amores ey.

- Tardey mya madre na fria fontana

Cervos do monte volviam a áugua.

Os amores ey.

- Mentir mya filha mentir por amigo

Nunca vi cervo que volvess'o rio

Os amores ey.

- Mentir mya filha mentir por amado

Nunca vi cervo que volvess'o alto.

Os amores ey.

(RECKERT; MACEDO, 1996, p. 68).

\section{Para uma conclusão}

Esta minha comunicação, que iniciei fazendo considerações sobre poesia e ficção científica, penso poder dizer-se que contém um tema geral na proposta de um novo Iluminismo tanto dos séculos XII e XIII como do século nosso contemporâneo. É que sinteticamente nela se fazem duas propostas referentes a dois temas culturais muito diferentes: a personalidade inventiva de Ramon Lull e os poetas peninsulares ibéricos das cantigas de amigo, pois julgo que embora distintos nas suas vivências humanas e desconhecendo-se mutuamente, hoje elas podem constituir referências complementares de um urgente projecto de ressurgimento cultural e humano, no qual a invenção e a inteligência se entrecruzam e mutuamente se implicam num possível novo mundo em transformação, onde o futuro se espelha no passado, para poder ser presente.

São Paulo, setembro de 2018. 


\section{Referências}

ARAN, Edson. Como será o trabalho no mundo 'volátil, incerto, complexo e ambíguo’. Folha de S. Paulo, São Paulo, 18 ago. 2018. Sobre tudo, Carreiras, [s. p.]. Disponível em: https://www1.folha.uol. com.br/sobretudo/carreiras/2018/08/1979151-esqueca-cracha-e-carteirade-trabalho-agora-e-tudo-volatil-incerto-complexo-e-ambiguo.shtml. Acesso em: 20 ago. 2018.

MELO E CASTRO, Ernesto Manuel Giraldes. No limite das coisas. Porto: Campo das Letras, 2003.

NEGROPONTE, Mário. A vida digital. Trad. Sérgio Tellaroli. São Paulo: Companhia das Letras, 1995.

O’NEILL, Alexandre. Poesias Completas 1951/1981. Prefácio de Clara Rocha. Lisboa: Imprensa Nacional/Casa da Moeda, 1982.

PALMA, Ana da. Ler e reler Ursula Kroeber Le Guin. Disponível em: https://aideia.blog/revista. Acesso em: 14 ago. 2018.

RECKERT, Stephen; MACEDO, Helder. Do Cancioneiro de Amigo. Lisboa: Assírio \& Alvim, 1996.

ROD, Wolfgang. O caminho da filosofia: dos primórdios até o século XX. Brasília: Editora da UNB, 2008.

Recebido em: 28 de outubro de 2019. Aprovado em: 15 de dezembro de 2019. 